\title{
Income-related inequality in gambling: evidence from Italy
}

\author{
Giuliano Resce $^{1} \cdot$ Raffaele Lagravinese $^{2} \cdot$ Elisa Benedetti $^{1} \cdot$ Sabrina Molinaro $^{1}$
}

Received: 22 February 2019 / Accepted: 27 September 2019

(c) Springer Science+Business Media, LLC, part of Springer Nature 2019

\begin{abstract}
In this paper we document the income-related inequality in gambling. We employ a novel database from 2014-2017 waves of the Italian Population Survey on Alcohol and other Drugs (IPSAD) which also include information on the preferences for games of chance. Following the Erryegers Index, our findings suggest that traditional lotteries are concentrated among the richest individuals, while betting and new generation games tend to be pro-poor games. The decomposition of income-related inequalities reveals that pro-rich inequality observed in traditional games is mainly driven by gender, age, and working condition. Higher components of the pro-poor inequality observed in betting and new generation games come instead from income and age. Since the pro-poor games are also the major contributors of the growth in gambling turnover and the increase in gambling disorders, our results indicate that a relevant part of increasing social costs associated to gambling are more likely to be paid by the less-well off, and potentially most vulnerable members of the society.
\end{abstract}

Keywords Income $\cdot$ Gambling $\cdot$ Inequality $\cdot$ Italy

JEL classifications $\mathrm{I} 12 \cdot \mathrm{I} 14$

\section{Introduction}

Over the last decades, there has been a global expansion of the gambling market, driven both by technological innovations providing new gambling opportunities and by public policies liberalizing the market in order to fight the spread of illegal gambling and maximize tax revenues that could be derived from its legal forms (Korn 2000; Pickernell et al. 2004; Paton et al. 2009; Olason et al. 2011; Deans et al.

Sabrina Molinaro

sabrina.molinaro@ifc.cnr.it

1 Institute of Clinical Physiology (IFC), Italian National Research Council (CNR), Rome, Italy

2 Department of Economics and Finance, Università di Bari “A.Moro”, Bari, Italy 
2016). This phenomenon has generated a number of undesirable social outcomes (e.g., addiction, youth gambling, money laundering), that are raising concerns worldwide (Markham et al. 2016). To tackle them, several countries are currently implementing different levels of consumers' protection through the imposition of constraints on who can gamble (e.g., adults) under which circumstances and which games (Di Bella et al. 2015).

In this scenario, an outstanding example is represented by the Italian gambling market, which in the last two decades has risen exponentially and currently constitutes the largest European one and among the most important in the world. While the Italian GDP represents only 3 per cent of the world economy, the country accounts for 22 per cent of the global expenditure on gambling (Guiso 2016).

This increase has been led by a process of reforms that have considerably liberalized the market and increased the supply of gambling products both through the number of licenses allowed and the introduction new products: Superenalotto (a particular form of numerical game) in 1997; Bingo halls in 1999; new slots and Video Lottery Terminals (two different kinds of entertainment machine) in 2003 and 2010 respectively ${ }^{1}$. The proliferation of games has increased not only the gambling revenues, but also the number of problematic gamblers both among young people and adults. Alarmingly, according to the Canadian Problem Gambling Index (CPGI) ${ }^{2}$ validated for Italy (Ferris and Wynne 2001; Colasante et al. 2013; Bastiani et al. 2013; Molinaro et al. 2018; Cerrai et al. 2018), the prevalence of gamblers in the general population (15-64 years old) who are at severe risk of developing addiction rose from 0.33 in 2007 to 1.04 in 2017 . This public health issue has become so important to prompt the Government to include the treatment of gambling addiction among the Essential Levels of Health Service (Decree 158/2012) ${ }^{3}$.

Despite the relevance of this phenomenon, in Italy there is a paucity of empirical literature on the distributional impact that it might have. Indeed, no previous study has explored the multifaceted relationship between consumption of different gambling products and the income-related characteristics of gamblers. This topic is particularly important because if the consumption of the set of products that predominantly lead the growth in public tax revenues was systematically concentrated among the more disadvantaged socio-economic groups, it would constitute a source of distributional concerns with strong policy implications, among which the challenge to the principle of progressivity at the basis of the Italian tax system (Gandullia and Leporatti 2018).

Furthermore, several studies suggest that specific types of gambling products are more associated with socio-economic conditions (Worthington 2001; Worthington et al. 2007) and gambling disorders (Deans et al. 2016; Buth et al. 2017).

\footnotetext{
1 https:/www.ilsole24ore.com/art/notizie/2017-09-21/cronologia-liberalizzazione-gioco-tappe-principali170952.shtml?uuid=AE6ztQXC.

2 Developed in 2001 by Ferris and Wynne, the CPGI screening test was validated in its Italian version by Colasante et al. (2013) and it is used in the IPSAD survey to assess the prevalence of problematical gambling behavior in the general population.
}

${ }^{3}$ LEA is a list of health care services that the central government requires to be guaranteed in all Italian Regions. 
In the Italian context it has been shown that some types of games have a strong association with gambling disorders (Scalese et al. 2016; Cavalera et al. 2018). A higher consumption of these games by less well-off individuals would signal that poorer people are also those more likely to pay the social costs of problematic gambling.

So far, the existing economic literature on income-related inequalities in the adoption of risk behaviors has mainly focused on obesity, smoking and alcohol drinking (Ljungvall and Gerdtham 2010; Costa-Font et al. 2014; Carrieri and Jones 2016). The few empirical studies investigating the distributional consequences of lottery play show conflicting results (Combs et al. 2008; Garrett and Coughlin 2009; Ghent and Grant 2010; Beckert and Lutter 2013).

The present work aims at shading light on this topic by applying the corrected Concentration Index proposed by Erreygers (2009) to the individual data from the 2014 and 2017 waves of the Italian Population Survey on Alcohol and other Drugs (IPSAD) ${ }^{\circledR}$. This indicator allows us to measure the inequality of gambling in relation to the socioeconomic position of individual gamblers. On this basis we identify prorich and pro-poor games on a set of three categories of gambling products: Traditional games (Scratchcards, Instant Lottery, Lotto, and Bingo); Betting (Football pools and Sport betting); New generation games (Slot machines and Texas hold'em). Then, we apply a regression-based decomposition method for rank-dependent inequality measures to investigate what are the sources of the income-related inequality observed. This gives us the opportunity to assess the relative contribution of income, education, employment and demographic characteristics to inequality. The results of these analyses provide empirical evidence to answer the debated question of who is paying the most the increasing gambling revenue and the related social costs in Italy, and what are the factors on which policy making may act to tackle this source of inequality. Furthermore they provide useful insights into the possible unintended effects of new public policies aimed either at liberalizing or at limiting the supply of specific gambling products.

The remainder of the paper is organized as follows: Section 2 provides an up-todate description of the evolution of the Italian gambling market, Section 3 presents the literature review; Section 4 describes the database employed; Section 5 illustrates the methodological approach; Section 6 presents and discusses the results of the empirical estimations and Section 7 concludes.

\section{The spread of gambling in Italy}

The massive growth of the Italian gambling market is proved by the $434 \%$ increase in the gross turnover ${ }^{4}$, which in 17 years (2000-2017) passed from 19 to more than 101.5 billions euros, with to major peaks in 2003 and 2011 (UPB Parliamentary Budget Office 2018). It is worth noticing that in Italy the organization and conduction of games and betting are reserved to the government, which operates through concessions to private operators in order to guarantee both the contrast to the illegal

\footnotetext{
${ }^{4}$ The gross gambling turnover refers to the actual amount gambled by participants with gambling operators.
} 
market and consumer protection and, due to the high addictive potential of this activity, the health and income of gamblers. Considering its economic relevance, this sector guarantees an important source of revenues for the central government, sustained by the high demand even in the periods of economic crisis. In ten years the tax revenues for the government increased from around 7 billions in 2006 to more than 10 billions in 2016 (corresponding to $10.8 \%$ of the gross turnover), making up $0.6 \%$ of the Italian GDP and more than $2 \%$ of the overall tax revenues. Interestingly, this increase has been mainly driven by the increased demand, as since 2006 with the declared aim to contrast illegal gambling, the central government has been applying a progressive reduction in the level of taxation on most games (UPB Parliamentary Budget Office 2018). With the same objective, there has been the introduction of some types of games (poker online) and the increase in the number of betting points and in public places as bars and tobacco shops.

Table 1 groups the gambling products currently authorized on the Italian market in three broad categories: Traditional games (Lotto, numerical games such as Superenalotto and Win for Life, lotteries, and Bingo), Betting (sport betting and horse racing), and New generation games (remote gambling such as online Poker and Texas hold'em, New Slots/AWP, Video-Lotteries/VLT, entertainment machines with non-monetary prizes). Traditional games (the first to be introduced in Italy, with Lotto back in 1620), that in 2006 accounted for $41 \%$ of the total turnover, have experienced a relative growth until 2011, when a relevant decrease started leading them to make up only $19 \%$ of the total gross turnover in 2017. Betting products, forming until 2013 a relatively small share of the market, thanks to the expansion of the betting offer, registered a substantial increase starting from 2014 with an yearly growth rate of almost $27 \%$, mainly driven by sport betting (which account today for more than $95 \%$ of the sector). This is mainly due to the increasing payout (84\% in 2017) which makes it attractive for gamblers, the constant reduction in the level of taxation (calculated on the difference between gross turnover and payout, diminished from $11 \%$ in 2006 to $2.6 \%$ in 2016), the introduction of the online betting (now constituting almost half of the share of bets) and, thanks to the entering into the market of several national and foreign operators allowed by Law n.190/2014, the consequent proliferation of betting points (UPB Parliamentary Budget Office 2018), coupled with massive advertisement campaigns. The introduction of new generation games, together with sport betting, are the main contributors to the impressive increase of the gambling turnover observed in the last 15 years. This is mainly due to the legalization of the New slots - AWP, a particular type of entertainment machines characterized by small bets ( 1 euro), fast playing time and relatively modest winnings (100 euros). Legalized in 2003, when they accounted for only $2 \%$ of the total gross turnover, new slots became so popular that in 2006 already constituted alone $43 \%$ of the total gross turnover. The VLT, similar to new slots but with higher bets and higher payout, two years after their introduction in 2010 had already attracted almost $25 \%$ of the overall collection of bets, share remained essentially stable until today. These processes altogether substantially increased the revenues from the gambling market both for operators and for the State and definitely changed the panorama of the gambling supply in Italy: now $69 \%$ of the total gross turnover is taken by New generation games, $12 \%$ by Betting and $19 \%$ by Traditional games. 


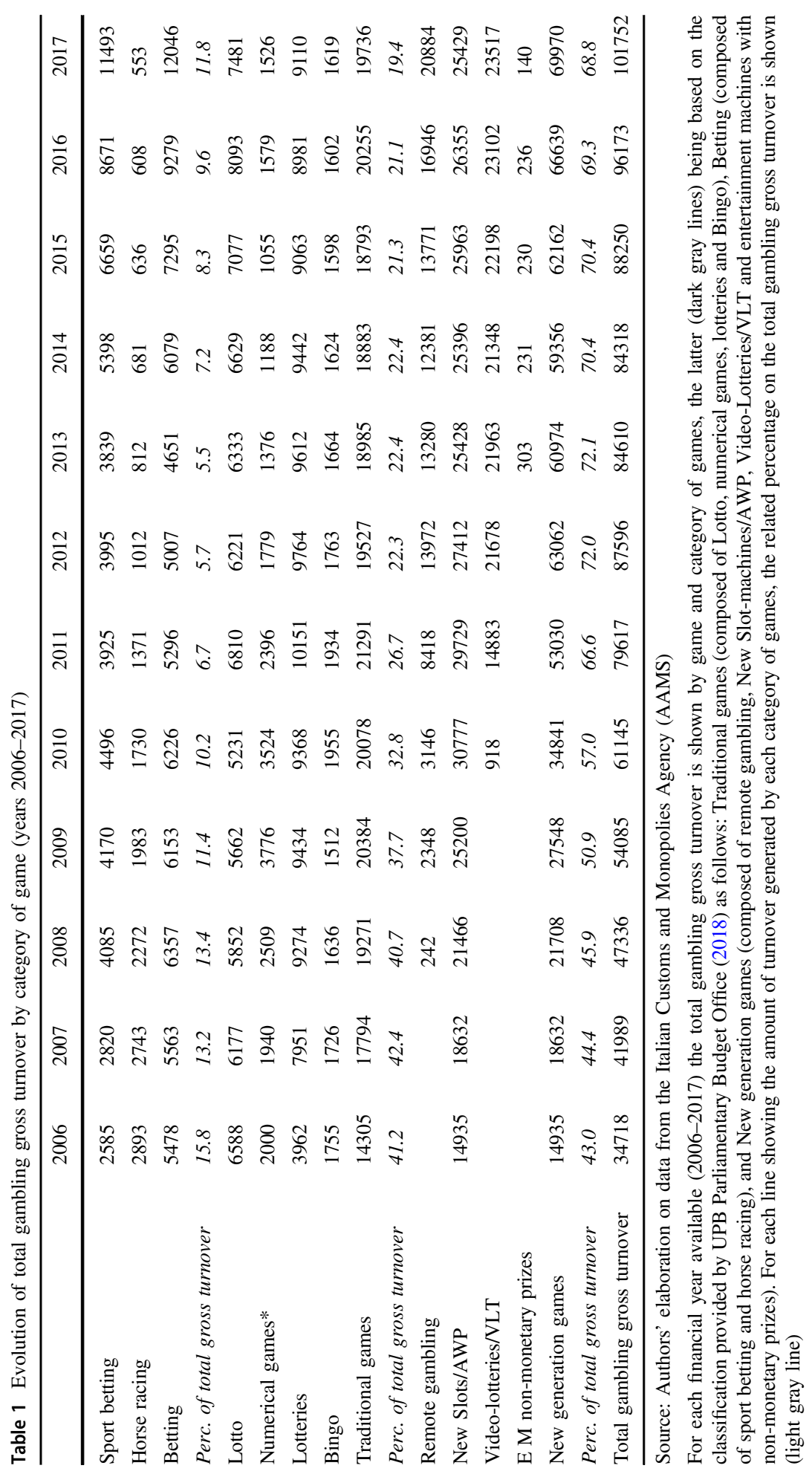




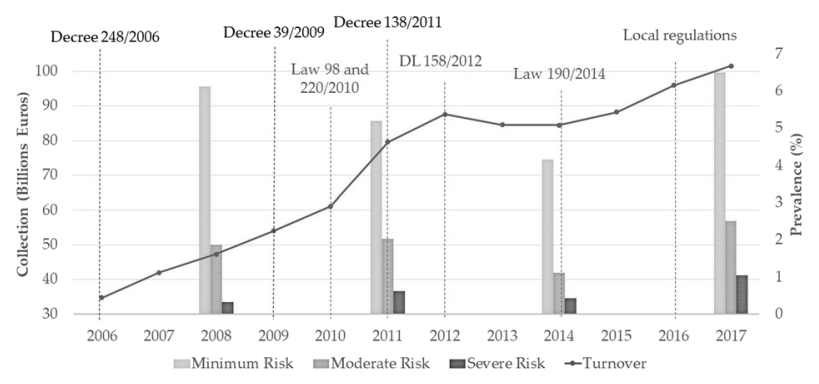

Fig. 1 Gambling turnover, prevalence of gabling severity (PGSI), and the most important gambling reforms in Italy (years 2006-2017). Source: Authors' elaboration on data from the Italian Customs and Monopolies Agency (AAMS) and authors' elaboration on IPSAD ${ }^{\circledR}$. Notes: Decree 248/2006: Market open to Foreign Operators; Decree 39/2009: Liberalization of Video Lottery Terminals (VLT); Law 98 and 220/ 2010: Introduction concept of addiction and ban on underage gambling; Decree 138/2011: Liberalization of Online Gambling; DL 158/2012: Pathological gambling included in the Essential Levels of Health Service (LEA); Law 190/2014: Funding for prevention and treatment; Local regulations: Local authorities to rule sale points and relevant criteria

The proliferation of games was associated with an increase in demand with related increases also in pathologies linked to pathological gambling. The IPSAD ${ }^{\circledR}$ survey results among the general population aged 15-64 tell us that in the last years, the prevalence of gamblers (calculated on individuals having gambled at least once in the last year) which in 2014 was $27.9 \%$ increased until reaching $42.8 \%$ in 2017 (Cerrai et al. 2018). As Fig. 1 shows, so has been also for the share of those gamblers that, due to their gambling behavior, can be classified as moderate and at-risk gamblers (from 5.6\% in 2014 to $8.3 \%$ in 2017). Among the student population aged 15-19, the prevalence, which in 2008 was $40.3 \%$, increased until 2011 when it reached $46.8 \%$, to decrease at $36.9 \%$ in 2017. Compared to the other European countries the prevalence among those aged 16 is one of the highest in Europe (Molinaro et al. 2018).

\section{Related literature}

The empirical study of the socio-economic determinants of gambling is still largely unexplored in Italy. Due to the limited availability of data, the few studies conducted so far have been bounded in their analysis both concerning the level of geographical detail and the games set considered. They found that gambling products are generally regressive at a regional level (Gandullia and Leporatti 2018) and that the effect of income on gambling expenditure is larger among households from the working class, lower educated and residing in the South of Italy (Sarti and Triventi 2012).

In order to understand the possible distributive effects of gambling, a consistent amount of research has instead been conducted in other countries to investigate if the propensity to gamble is heavenly distributed in the population or if on the contrary it is more concentrated among some social groups. This is particularly relevant to policy making, as the expansion of state gambling products continues, there is substantial public controversy surrounding the use of gambling as a means of raising public funds (Kearney 2005). In fact, although gambling is a voluntary activity, if 
both its participation and the pattern of expenditure were conditioned by social features like low education and low income levels, it may work to the relative detriment of individuals belonging to the most vulnerable social segments thus contributing to the perpetration of social inequality and deepen the economic problems that must be addressed by public support programs (Madhusudhan 1996; Rivenbark and Rounsaville 1996; Szakmary and Szakmary 1995). Research on the distributive effects of gambling has mainly concentrated on lottery play, finding that low-income and the propension to gamble are more likely to engage in state lotteries and to spend a higher percentage of their income on lottery play than do wealthier individuals (Suits 1977; Clotfelter 1979; Clotfelter and Cook 1987, 1989; Scott and Garen 1994; Hansen 1995; Worthington 2001). Taking account of these observations and of the fact that state profits on the sale of gambling products are equivalent to an implicit tax, a number of studies went further identifying the extent of regressivity of public taxation on gambling (Clotfelter and Cook 1987; Farrell and Walker 1999; Laitner 1999; Layton and Worthington 1999; Worthington 2001; Worthington et al. 2007; Beckert and Lutter 2009, 2013; Coughlin and Garrett 2009; Perez and Humphreys 2011; Crowley et al. 2012).

As to the reason why low-income people gamble, although no definite answers have yet been provided (Ariyabuddhiphongs 2011), experimental studies found both that lotteries are more attractive for poor people because they provide an opportunity to correct for low-income status, and that part of their appeal is that they are one of the few opportunities available to the poor for a sudden increase in wealth (Haisley et al. 2008). In this framework, gambling may act as a mean for coping with the discrepancy between the desired socio-economic status and the few options viable of achieving it via traditional channels (i.e., savings). Particularly, prior empirical literature (Friehe and Mechtel 2017) has proved that a strong status orientation (i.e., importance attached to one's position relative to the others) among households with positional concerns is highly correlated with both the participation and the higher expenditure in gambling.

Whilst few studies have focused on more than a single game classification (Grote and Matheson 2012), recent research has pointed at the fact that the effects of gambling vary across the various categories of gambling participation. In fact, several studies suggest that specific types of gambling products are more associated with socio-economic conditions (Worthington 2001; Worthington et al. 2007). Particularly, the payout rate has been identified as one of the main factors that, besides the jackpot, has an impact on consumer preferences and demand (Quiggin 1991). It is therefore presumable that low-income people willing to leapfrog the societal hierarchy may be more attracted by those games which offer a higher payout.

As shown in Table 2, the payout guaranteed by the Italian legislation for the different categories of games varies greatly, with New generation games and Betting products paying back to gamblers the higher amounts.

Previous research has also found that low socio-economic status interferes with behavioral control and impair resilience mechanism that favor the adoption of risk behaviors and unhealthy life-styles, like cigarette, alcohol and substance use, and the development of related addictions (see Costa-Font et al. 2014; Carrieri and Jones 2016). In the Italian context, it has to be noted that those games which offer the higher payout are not only the ones that drove the increase in gambling turnover over 
Table 2 Gambling payout by category of lotteries

\begin{tabular}{lllll}
\hline & Min. & Median & Mean & Max. \\
\hline Betting & $50 \%$ & $78 \%$ & $73 \%$ & $85 \%$ \\
Traditional games & $35 \%$ & $70 \%$ & $63 \%$ & $76 \%$ \\
New generation games & $74 \%$ & $85 \%$ & $85 \%$ & $97 \%$ \\
\hline
\end{tabular}

Source: Italian Customs and Monopolies Agency (AAMS), 2016

Payout refers to the percentage of the total turnover that is paid back to gamblers in the form of winnings. It is shown by category of games as classified in Table 1 following UPB Parliamentary Budget Office (2018). Columns (2) and (5) report minimum and maximum payout respectively, column (3) and (4) report median and average payout respectively

the last decade, but are also those proven to be more associated to the development of addiction. In particular, slot machines, strategy-based games (such as poker, horse racing, and sport betting) and online games have the strongest associations with gambling disorders (Scalese et al. 2016; Cavalera et al. 2018). We therefore expect that the categories of games with higher payout and higher addictiveness, i.e., Betting and New generation games, are more concentrated among the less well-off, lowereducated individuals.

In order to provide some policy input into the undesirable distributive consequences of the expansion of the gambling industry and the potential for problem gambling, the present paper aims at contributing to the strain of literature analyzing gambling as a possible source of income inequality. Contributing to fill the gap in the Italian literature, it deepens the analysis by breaking down gambling into categories of games using nationally representative data. Furthermore, in order to provide meaningful inputs on which policy makers could effectively act, it identifies the driving factors of the income inequality observed.

\section{Data}

Data were drawn from the 2014 and 2017 Italian Population Survey on Alcohol and other Drugs (IPSAD ${ }^{\circledR}$ ), a cross-sectional survey conducted since 2001 by the Institute of Clinical Physiology of the Italian National Research Council. IPSAD ${ }^{\circledR}$ is the only study providing nationally representative data on substance use, gambling and other risk behaviors adopted by the Italian population aged 15-74. Data are collected through postal self-administered and anonymous paper and pencil questionnaires from a proportional stratified randomized sample, extracted from the registry lists of selected municipalities in the sampling frame. The response rate of participants both in the 2014 and in the 2017 waves was about $35 \%$. The present analysis is restricted to those individuals $(n=7348$ out of 8113 in $2014 ; 5773$ out of 10,467 in 2017) who reported full information about gambling habits, income, sex, age, region, education, and working condition.

The survey contains information on gambling engagement and attitudes as well as detailed information on the patterns of use of 8 specific games: Scratchcards, Instant 
Lottery, Lotto, Football pools, Bingo, Slot machines, Sport betting, and Texas hold'em. Following UPB Parliamentary Budget Office (2018), we categorized these games into three main categories: Traditional games (Scratchcards, Instant Lottery, Lotto, and Bingo); Betting (Football pools and Sport betting); New generation games (Slot machines and Texas hold'em). With the aim of estimating and comparing income-related inequalities in gambling activity by category of game, we identify the Gamblers (1) those individuals who gambled at least once in the last year, and the non-Gamblers (0) otherwise.

Table 2 presents the results of the IPSAD ${ }^{\circledR}$ survey for our sample in the three macro-categories of games referred in this section. On the basis the CPGI (Canadian Problem Gambling Index) assessment, 2.74 per cent of gamblers in traditional games was classified as Severe Problem in 2014 and 2.39 per cent of gamblers was classified as Severe Problem in 2017. In line with previous studies (Scalese et al. 2016; Cavalera et al. 2018), those percentages increase significantly when gamblers in Betting and gamblers in New generation games are considered. In fact, the share of Severe Problem gamblers among those playing Betting was 3.8 per cent in 2014 and 2.86 per cent in 2017. Furthermore the gamblers in New generation games classified as Severe Problem were 10.53 per cent in 2014 and 12.5 per cent in 2017.

In IPSAD ${ }^{\circledR}$, self-reported individual gross income level is measured by means of six classes: 0 or less; 0-15,000; 15,000-36,000; 36,000-70,000; 70,000-100,000; more than 100,000 euros. In order to obtain a continuous variable for individual income, we perform a statistical matching between IPSAD $^{\circledR}$ and the last Italian version of EU's Statistics on Income and Living Conditions (EU-SILC 2015 related to income in 2014), which contains information for almost 70 thousand individuals (ISTAT 2018). For the statistical matching, we use the nearest neighbor distance hot deck technique (D'Orazio 2017). Our function searches in EU-SILC the nearest neighbor of each individual in IPSAD $^{\circledR}$, according to a distance computed on five variables: sex, age, region, education, and working condition. Moreover, based on the six income classes in IPSAD ${ }^{\circledR}$, six income donation classes are defined on EUSILC, in this way for any individual in income class in IPSAD $^{\circledR}$ is selected an individual in the same income class in EU-SILC.

\section{Methods}

With the aim of estimating and comparing income-related inequalities in gambling activity by type of game, we identify as gambler each individual having gambled at least once in the past year (we also perform robustness check increasing the frequency to weekly, those results are shown in the appendices). In order to compare income-related inequalities in gambling for the three category of games described above (traditional games, betting, new generations), we use the Erreygers (2009) Index (EI). The Erreygers Index is a rank-dependent inequality measure that can be calculated as follows:

$$
E I(h)=\frac{8}{b_{h}-a_{h}} \operatorname{cov}\left(h_{i}, R_{i}\right)
$$


where the vector $h=\left(h_{1}, h_{2}, \ldots h_{n}\right)$ represents the gambling status of the whole population. In our case, for each individual $i, h_{i}$ takes the value 1 or 0 depending on whether s/he is a gambler or not, $R_{i}$ is a monotonically increasing function of income measuring individual's relative position in the income distribution, bounded between 0 (least well-off) and 1 (most well-off). In other words, $R_{i}$ designates the $i$ th individual's fractional rank within the income distribution (Carrieri and Wübker 2013). Finally, $b_{h}$ and $a_{h}$ in (1) represent the upper and the lower bound of the dependent variable $\left(h_{i}, i=1, \ldots, n\right)$, which in our case are 1 and 0 .

As shown in Erreygers (2009), the value of $E I(h)$ is included in:

$$
-\frac{4\left(b_{h}-\mu_{h}\right)\left(\mu_{h}-a_{h}\right)}{\left(b_{h}-a_{h}\right)^{2}} \leq E I(h) \leq+\frac{4\left(b_{h}-\mu_{h}\right)\left(\mu_{h}-a_{h}\right)}{\left(b_{h}-a_{h}\right)^{2}}
$$

where $\mu_{h}$ is the mean of the dependent variable $(h)$. In our case the positive (negative) values of $E I(h)$ indicates that the occurrences of ones (being gambler) in $h$ are more concentrated among individuals with higher (lower) levels of income. The first case is generally termed as pro-rich inequality, while the second case is defined as pro-poor inequality (Carrieri and Jones 2016). As a measure for income, we use the individual gross income self-reported in IPSAD ${ }^{\circledR}$ matched with ISTAT (2018). As robustness check, we also estimate Income-related inequality using the six classes on income (rather than the continuous matched measure) originally included in IPSAD $^{\circledR}$.

It is worth recalling that, in order to understand the relationship between income and gambling participation, a standard binary model (logit/probit) can capture the decision to (not) participate as well (see, among others, Friehe and Mechtel 2017). As shown in Wagstaff et al. (1991), there is a well-established relationship between Concentration Indices (as the Erreygers Index) and the slope of regression of $h_{i}$ on $R_{i}$. Khaled et al. (2018) demonstrated that the two results are consistent in terms of significance (we have done this analysis by a probit model, the results are reported in Tables 11 and 12 in the appendices). However, the Erreygers Index, compared with other techniques, is the only one that satisfies four desirable properties for estimating the extent to which the distribution of a specific item (as gambling activity) is far away from an income-neutral distribution (Kjellsson and Gerdtham 2013; Carrieri and Wübker 2013):

1. Transfer: ceteris paribus a small transfer of gambling activity from a richer (poorer) to a poorer (richer) individual translates into a pro-poor (pro-rich) change in the index;

2. Mirror: the inequality indices of gambling and non-gambling are mirror images of each other; that is, $E I(h)$ is equal to the absolute value of $E I(1-h)$, but has the opposite sign;

3. Level independence: an equal increment of gambling activity for all individuals does not affect the index; that is, the index is invariant to scalar addition even when the bounds of the variable are kept constant. In our context, this means that the index does not change in magnitude when there is an increase in gambling activity from a year to another (e.g., 2014-2017) while keeping absolute inequalities unchanged. In addition, these characteristics are particularly appropriate for this study in which we want to compare inequalities 
Table 3 Percentage distribution of gabling severity (CPGI) by type of game $(2014,2017)$

\begin{tabular}{lllllll}
\hline & Year & N. obs. & No risk & Low risk & Moderate risk & Severe problem \\
\hline Traditional games & 2014 & 438 & 76.03 & 15.75 & 5.48 & 2.74 \\
& 2017 & 376 & 75.00 & 15.43 & 7.18 & 2.39 \\
\multirow{2}{*}{ Betting } & 2014 & 438 & 60.87 & 26.52 & 9.13 & 3.48 \\
& 2017 & 350 & 76.57 & 12.57 & 8.00 & 2.86 \\
New generation & 2014 & 95 & 44.21 & 28.42 & 16.84 & 10.53 \\
& 2017 & 64 & 53.13 & 15.63 & 18.75 & 12.50 \\
\hline
\end{tabular}

Source: Authors' elaboration on IPSAD ${ }^{\circledR}(2014 ; 2017)$

The profiles of gambling severity are defined on the basis of CPGI screening test (Ferris and Wynne 2001; Colasante et al. 2013). Number of Observations refers to individuals who have gambled at least once in the last 12 months and completed the CPGI questionnaire. The CPGI is a screening scale consisting of 9 questions related to gambling behavior. The scale is composed of multiple choice questions (Never $=0$, Sometimes $=1$, Often $=2$, Almost always $=3$ ), with a score range between 0 and 27: - score lower than 1 characterizes the social player "No Risk" gambler; - from 1 to 2 points a low risk level is classified as "Low Risk" gambler; - from 3 to 7 the level of risk becomes moderate "Moderate Risk" gambler; - equal to or greater than 8 indicates a problematic condition, defined as "Severe Problem" (see Ferris and Wynne 2001)

in gambling activity by type of game, and prevalence of use strongly differs among different games (the prevalence of use of Traditional games is higher than Betting which is higher than New generation games, see observation in Table 3);

4. Cardinal invariance: a linear transformation of the gambling variable $(h)$ does not affect the value of the index; that is, the measured degree of inequalities is the same, irrespective of the cardinal scale of the gambling variable.

Following the procedure in O'Donnell et al. (2007; p. 159), in order to decompose the Erreygers Index we use a two-steps process. In the first step, the individual gambling status $\left(h_{i}\right)$ is modeled as follows:

$h_{i}=\alpha+\beta_{\text {inc }} I N C_{i}+\beta_{g e n} G E N_{i}+\beta_{\text {age }} A G E_{i}+\beta_{\text {edu }} E D U_{i}+\beta_{\text {wor }} W O R_{i}+\beta_{\text {loc }} L O C_{i}+\varepsilon_{i}$

Where $I N C_{i}, G E N_{i}, A G E_{i}, E D U_{i}, W O R_{i}, L O C_{i}$ represent respectively: individual income, gender (Male $=1$ ), age, education (Degree or more $=1$ ), working condition (one dummy for retired and one dummy for working), and location (Southern regions $=1$ ). The choice of these variables is driven by previous empirical studies showing that gender and age matter in gambling choices (Ariyabuddhiphongs 2011; Perez and Humphreys 2011; Beckert and Lutter 2013; Friehe and Mechtel 2017), that higher educated people tend to play less (Beckert and Lutter 2009, 2013; Grote and Matheson 2012; Friehe and Mechtel 2017), and that the working condition is also associated with gambling and problematic gambling, and in Italy there is a higher prevalence of gambling and problematic gambling in Southern regions (see, among others, Scalese et al. 2016; Buth et al. 2017; Molinaro et al. 2018; Cerrai et al. 2018; Cavalera et al. 2018; Gandullia and Leporatti 2018). Furthermore, the dummy variable for Southern regions takes into account the fact that Italy is historically a dual country in many dimensions including health and health care (see Greco et al. 2018; Lagravinese et al. 2019). In the second step, using coefficients form (3), $E I(h)$ 
can be decomposed as follows:

$$
\begin{aligned}
E I(h)= & 4 *\left[\beta_{\text {inc }} * G C I(I N C)+\beta_{\text {gen }} * G C I(G E N)+\beta_{\text {age }} * G C I(A G E)+\right. \\
& \left.+\beta_{\text {edu }} * G C I(E D U)+\beta_{\text {wor }} * G C I(W O R)+\beta_{\text {loc }} * G C I(L O C)+G C I\left(\varepsilon_{i}\right)\right]
\end{aligned}
$$

According to (4), the contribution of income, gender, age, education, working condition, and location to overall income-related inequalities in gambling depends on both their own generalized concentration index with respect to income $(G C I()$ see Erreygers 2009) and their marginal effect on $h(\beta)$ taken from (3) (O'Donnell et al. 2007; Carrieri and Jones 2016). The last term in (4) is the residual component, formally is the generalized concentration index for the error term in (3), it reflects the income-related inequalities in gambling that cannot be explained by variation in individual income, gender, age, education, working condition, and location (O'Donnell et al. 2007; Carrieri and Wübker 2013). By coupling the application of a regression method with a income distribution analysis $G C I()$, the two steps procedure presented in (3) and (4) allow to partition total inequality observed into the specific inequalities associated with each regressor (Doorslaer et al. 2004). In other words, by means of Eqs. (3) and (4), regressors' contribution to total income-related inequality detected in gambling is decomposed into two parts: the impact of each regressor on the probability to participate in gambling, as measured by the $\beta \mathrm{s}$ in (3), and each regressor's degree of unequal distribution across income ranking, measured by the generalized concentration index $G C I()$. As shown by previous literature, this can be a transparent tool for unpacking the mechanisms contributing to a degree of incomerelated inequality observed in a specific behavior (Carrieri and Wübker 2013).

\section{Results}

\subsection{Gambling and Income: a descriptive perspective}

A first representation of the relationship between income and gambling participation is given by the descriptive statistics presented in Table 4.

Taking the whole sample, the average income is 20,046.11 in 2014 and 23,533.30 in 2017, while the median income is 16,314 in 2014 and 20,363 in 2017. Moving to gamblers, no matter the game played, Table 4 shows that mean and median income are substantially in line with the whole sample both in 2014 and 2017. Some differences in income can be observed differentiating by games. In particular, taking gamblers in Traditional games both the mean and median income in this category are higher than mean and median income taking the whole sample and taking gamblers without differentiating in game. Furthermore, gamblers in Betting and New generation games show lower levels in mean and median income compared with the others. These results are consistent in 2014 and in 2017. Summarizing, gamblers in Traditional games show a higher income level, while gamblers in Betting and New generation games have a lower income level, and this evidence is confirmed both in 2014 and 2017. Regarding age and gender distribution, Table 4 shows that the percentage of males is higher among gamblers in Betting and New generation games, and the average age is higher among gamblers in Traditional games. 
Table 4 Descriptive statistics for gambling activity

\begin{tabular}{|c|c|c|c|c|c|}
\hline & \multirow[t]{2}{*}{ Year } & \multicolumn{2}{|l|}{ Income } & \multicolumn{2}{|c|}{ Gender and age } \\
\hline & & Median & Mean & $\%$ of males & Average age \\
\hline \multirow[t]{2}{*}{ Whole sample } & 2014 & 16314.50 & 20046.11 & 46.14 & 44.02 \\
\hline & 2017 & 20363.00 & 23533.30 & 48.76 & 44.96 \\
\hline \multirow[t]{2}{*}{ Gambler } & 2014 & 17266.00 & 20297.93 & 62.35 & 42.30 \\
\hline & 2017 & 20349.50 & 23829.06 & 57.78 & 44.28 \\
\hline \multirow[t]{2}{*}{ Traditional } & 2014 & 19545.50 & 22305.65 & 66.63 & 47.36 \\
\hline & 2017 & 21563.00 & 24761.68 & 65.70 & 49.17 \\
\hline \multirow[t]{2}{*}{ Betting } & 2014 & 8756.50 & 13990.40 & 87.09 & 34.67 \\
\hline & 2017 & 15514.50 & 20020.09 & 72.43 & 41.01 \\
\hline \multirow[t]{2}{*}{ New generation } & 2014 & 9750.00 & 15876.30 & 86.58 & 35.17 \\
\hline & 2017 & 15143.00 & 16060.93 & 83.33 & 39.88 \\
\hline
\end{tabular}

Observations $=7348$ (2014); 5773 (2017). Gambler $=$ at least one in the last 12 months. Columns (2) and (3) report median and average income respectively, column (4) reports share of males and column (5) reports average age on the whole sample, sub-sample of gamblers, gamblers in traditional games, gamblers in betting, and gamblers in new generation games

Table 5 Income-related inequality by type of game (2014, 2017)

\begin{tabular}{llllll}
\hline & Year & Obs. & EI & Std. error & $p$-value \\
\hline Gambler & 2014 & 1891 & 0.012 & 0.012 & 0.320 \\
& 2017 & 2416 & 0.011 & 0.015 & 0.455 \\
Traditional & 2014 & 896 & $\mathbf{0 . 0 4 0}$ & 0.009 & 0.000 \\
\multirow{2}{*}{ Betting } & 2017 & 901 & $\mathbf{0 . 0 4 7}$ & 0.011 & 0.000 \\
& 2014 & 364 & $\mathbf{- 0 . 0 3 3}$ & 0.006 & 0.000 \\
New generation & 2014 & 149 & $\mathbf{- 0 . 0 1 3}$ & 0.004 & 0.001 \\
& 2017 & 96 & $\mathbf{- 0 . 0 1 3}$ & 0.004 & 0.001 \\
\hline
\end{tabular}

Observations $=7348$ (2014); 5773 (2017). Gambler $=$ at least one in the last 12 months; significant EI in bold. Column (2) reports number of observations, in column (3) the Erreygers Index is reported, column (4) reports standard errors, and column (5) report $p$-values for gamblers, gamblers in traditional games, gamblers in betting, and gamblers in new generation games

\subsection{Income-related inequality in gambling}

Table 5 reports the estimates of the Erreygers Indices, which measure the level of income inequalities in all games examined. As shown in the first two rows in Table 5, both in 2014 and 2017 taking all games together, gambling seems to be a prerogative of higher income people, since the Erreygers Index is positive although not significant. This result changes instead when we break down the analysis by the abovementioned three categories of games: Traditional, Betting, and New generation. As far as traditional games are concerned, the Erreygers index is positive, significant, and increasing from 2014 to 2017 . The intensity of income-related inequality 
increases from 0.040 to 0.047 , signaling that this category of games not only is more practiced by higher income people, but its pro-richness increases over time. Opposite results are instead found when analyzing betting and new generation games, which are both preferred by lower income people. Regarding betting, the Erreygers index is -0.033 in 2014 and -0.036 in 2017 , while for new generation games it is -0.013 both in 2014 and in 2017. These results show that both categories of game are preferred by lower-income individuals and the income-related inequalities are slightly increasing over-time. As reported in Table 8 in the appendices, the main evidences provided in Table 5 are confirmed, although less significantly due to the reduction in the number of observations, when we consider people who gamble at least weekly in the last 12 months.

As a further robustness check, in Table 9 we report the Income-related inequality estimates using the six classes on income (rather than the continuous matched measure) originally included in IPSAD. The main evidences provided in Table 5 are confirmed by this additional analysis, meaning that the results presented here are independent from the matching procedure used.

Since the increasing gambling turnover observed in the last decade is mainly due to betting and new generations games (Table 1), the results in Table 5 show that less well-off people are those who are paying more this massive spread of gambling. Furthermore, since Betting and New generation games are also those more strongly associated with problematic gambling behaviors, we can reasonably assume that the growing social cost of gambling disorders in Italy are more likely to be borne by the less-well of, and therefore more vulnerable, segment of the society.

\subsection{Decomposition of inequality in gambling}

The decomposition of the income related inequalities is reported in Table 6 (2014) and Table 7 (2017). As mentioned in Section 5, we follow the procedure proposed by O'Donnell et al. (2007; p. 159) and, on the basis of previous studies, we decompose the inequality to better investigate the contribution that income, gender, age, higher education, working condition, and the geographical location of residence (obtained using a dummy for Southern regions). Overall, we find a large heterogeneity in the contribution that these different components give to the overall gambling inequality.

Looking at the Traditional games (a pro-rich category), gender explains the $71 \%$ of total inequality in 2014 and the $58 \%$ in 2017 . This is due to the fact that both the association between being male and being gambler and the concentration index are positive (males are more traditional gamblers and have higher income). The direct contribution of income to the overall inequality is quite modest and negative in both 2014 and 2017 ( -10 and $-44 \%$ respectively). This pro-poor contribution is due to the fact that the partial effect of income on the use of traditional games is negative while the concentration index is positive both in 2014 and 2017. Age explains the $32 \%$ of income related inequality in 2014 and $90 \%$ of income related inequality in 2017 for traditional games. In both years, age has a positive partial effect on being gambler of traditional games, and it has a positive concentration index (older people are both traditional gamblers and have higher income). The direct effect of higher education is negative both in 2014 and 2017 ( -39 and $-50 \%$ respectively). This is due to the fact that having achieved a high educational level has a negative partial 
Table 6 Decomposition of income-related inequalities by gambling type (2014)

\begin{tabular}{|c|c|c|c|c|}
\hline Gambling type & $\beta$ & GCI & Contrib. & $\%$ Contrib. \\
\hline \multicolumn{5}{|l|}{ Traditional games } \\
\hline Gender $($ Male $=1)$ & 0.089 & 0.079 & 0.028 & 71.01 \\
\hline Income & 0.000 & 11067.040 & -0.004 & -10.33 \\
\hline Age & 0.001 & 4.575 & 0.013 & 32.39 \\
\hline Higher Education & -0.058 & 0.067 & -0.016 & -39.16 \\
\hline Working & 0.031 & 0.139 & 0.017 & 43.76 \\
\hline Retired & 0.031 & 0.045 & 0.006 & 14.32 \\
\hline South & 0.056 & -0.028 & -0.006 & -15.74 \\
\hline Total & & & 0.038 & 96.25 \\
\hline Residuals & & & 0.001 & 3.75 \\
\hline \multicolumn{5}{|l|}{ Betting } \\
\hline Gender $($ Male $=1)$ & 0.094 & 0.079 & 0.030 & -91.23 \\
\hline Income & 0.000 & 11067.040 & -0.016 & 49.73 \\
\hline Age & -0.002 & 4.575 & -0.031 & 94.81 \\
\hline Higher Education & -0.006 & 0.067 & -0.002 & 5.05 \\
\hline Working & -0.009 & 0.139 & -0.005 & 16.00 \\
\hline Retired & -0.014 & 0.045 & -0.003 & 7.86 \\
\hline South & 0.062 & -0.028 & -0.007 & 21.05 \\
\hline Total & & & -0.034 & 103.27 \\
\hline Residuals & & & 0.001 & -3.27 \\
\hline \multicolumn{5}{|c|}{ New generation games } \\
\hline Gender $($ Male $=1)$ & 0.038 & 0.079 & 0.012 & -94.42 \\
\hline Income & 0.000 & 11067.040 & -0.005 & 36.25 \\
\hline Age & -0.001 & 4.575 & -0.012 & 98.65 \\
\hline Higher Education & -0.002 & 0.067 & -0.001 & 4.30 \\
\hline Working & -0.004 & 0.139 & -0.002 & 19.20 \\
\hline Retired & -0.005 & 0.045 & -0.001 & 7.70 \\
\hline South & 0.013 & -0.028 & -0.001 & 11.73 \\
\hline Total & & & -0.011 & 83.42 \\
\hline Residuals & & & -0.002 & 16.58 \\
\hline
\end{tabular}

Observations $=7348$. Column (2) reports the marginal effects as estimated by Eq. (3), column (3) reports the Generalized Concentration Index, column (4) reports the contribution to Erreygers Index, and in column (5) the contribution to Erreygers Index is reported in percentage

effect on being traditional gamblers, and the concentration index is positive (higher educated people are less traditional gamblers and they are more rich). Both the working and retired condition have a positive effect on the inequality for traditional games: the working condition explains $44 \%$ of inequality in 2014 and the $39 \%$ of inequality in 2017, while the retired condition explains the $14 \%$ of inequality in 2014 and the $1 \%$ of inequality on 2017 . These results are due to the fact that working and retired people play more traditional games and that concentration indices are positive 
Table 7 Decomposition of income-related inequalities by gambling type (2017)

\begin{tabular}{|c|c|c|c|c|}
\hline Gambling type & $\beta$ & GCI & Contr. & $\%$ Contr. \\
\hline \multicolumn{5}{|l|}{ Traditional games } \\
\hline Gender $($ Male $=1)$ & 0.095 & 0.071 & 0.027 & 57.75 \\
\hline Income & 0.000 & 11987.822 & -0.021 & -43.91 \\
\hline Age & 0.002 & 4.250 & 0.042 & 90.25 \\
\hline Higher education & -0.076 & 0.077 & -0.024 & -50.30 \\
\hline Working & 0.034 & 0.132 & 0.018 & 38.51 \\
\hline Retired & 0.003 & 0.033 & 0.000 & 0.85 \\
\hline South & 0.040 & -0.022 & -0.004 & -7.62 \\
\hline Total & & & 0.040 & 85.53 \\
\hline Residuals & & & 0.007 & 14.47 \\
\hline \multicolumn{5}{|l|}{ Betting } \\
\hline Gender $($ Male $=1)$ & 0.086 & 0.071 & 0.024 & -68.35 \\
\hline Income & 0.000 & 11987.822 & -0.014 & 39.86 \\
\hline Age & -0.002 & 4.250 & -0.028 & 77.73 \\
\hline Higher education & -0.008 & 0.077 & -0.003 & 7.09 \\
\hline Working & -0.008 & 0.132 & -0.004 & 12.38 \\
\hline Retired & 0.015 & 0.033 & 0.002 & -5.67 \\
\hline South & 0.044 & -0.022 & -0.004 & 10.85 \\
\hline Total & & & -0.026 & 73.87 \\
\hline Residuals & & & -0.009 & 26.13 \\
\hline \multicolumn{5}{|c|}{ New generation games } \\
\hline Gender $($ Male $=1)$ & 0.026 & 0.071 & 0.007 & -54.86 \\
\hline Income & 0.000 & 11987.822 & -0.006 & 45.68 \\
\hline Age & 0.000 & 4.250 & -0.005 & 39.92 \\
\hline Higher education & -0.006 & 0.077 & -0.002 & 14.96 \\
\hline Working & -0.008 & 0.132 & -0.004 & 30.12 \\
\hline Retired & -0.003 & 0.033 & 0.000 & 3.05 \\
\hline South & 0.005 & -0.022 & 0.000 & 3.35 \\
\hline Total & & & -0.011 & 82.22 \\
\hline Residuals & & & -0.002 & 17.78 \\
\hline
\end{tabular}

Observations $=5773$. Column (2) reports the marginal effects as estimated by Eq. (3), column (3) reports the Generalized Concentration Index, column (4) reports the contribution to Erreygers Index, and in column (5) the contribution to Erreygers Index is reported in percentage

(they are more rich). Finally, the fact of residing in Southern region has a negative effect on income related inequality for traditional games $(-16 \%$ in 2014 and $-8 \% \mathrm{n}$ 2017). This is the combined effect of the positive partial effect of residing in the South, and a negative concentration index. In other words, people from South are more gamblers and less rich, and this contributes negatively to the pro-rich inequality observed in traditional games. 
Focusing on betting (a pro-poor category) we find that gender has a large and negative contribution to the income-related inequality ( $-91 \%$ in 2014 and $-68 \%$ in 2017). This is due to the combined effect of the partial positive contribution of being male to being a gambler of this category of games, and the positive concentration index of gender (males are more gamblers and more well-off and this contributes negatively to the pro-poor inequality observed in betting). The direct contribution of income on income related inequality on betting is 50\% in 2014 and $40 \%$ in 2017. As in the case of traditional games, higher income people tend to be less attracted by betting products and the concentration index is positive. Since betting is a pro-poor game, the negative partial effect of income to being gambler combined with the positive concentration index play now a positive role in explaining inequality. Age gives the higher contribution to income-related inequality in betting both in 2014 and 2017 (95 and 78\% respectively). As in the case of income, the negative partial effect of age on being betting gambler and the fact that age is pro-rich concentrated (Carrieri et al. 2017) contributes substantially and positively to the pro-poor inequality observed. Higher education has a small positive effect on income related inequality (5\% in 2014 and 7\% in 2017) since it has a negative partial effect on being gambler in betting and positive concentration index. The same is true for the working condition, which accounts for $16 \%$ of income related inequality in 2014 and for $12 \%$ in 2017. Interestingly, the contribution of being retired is positive in $2014(8 \%)$ and it is negative in $2017(-6 \%)$. This switching in the sign is due to the fact that the partial effect of being retired on being gambler in betting is negative in 2014 and positive in 2017 , and being retired has a positive concentration index in both the years observed. Finally, the dummy South explains the $21 \%$ of income related inequality in betting in 2014 and the $11 \%$ in 2017. People from the Southern regions tend to bet more gambler and the dummy South has a negative concentration index due to the lower level per-capita income that Southern regions have compared with the rest of Italy. This results are in line with Worthington et al. (2007) for Australia in which regional location are likewise significant in determining gambling expenditure.

Focusing on the income related inequality observed in the new generation games, we find that gender contributes negatively to it (-94\% in 2014 and $-55 \%$ in 2017). As in the case of betting, males tend to play more at new generation games and the concentration index is positive. The combined effect of these factors has a negative impact on the negative Erreygers index. The direct contribution of income is relevant in both years (36\% in 2014 and 46\% in 2017). Higher income people play less at new generation games, but the concentration index is positive and this contributes positively to the negative income related inequality observed for this category of games. The contribution of age in new generation games is even more relevant (99\% in 2014 and $40 \%$ in 2017). As in the case of betting, the higher the age, the lower the probability to play at new generation games, but the higher the age the higher the income. The combined effect of these factors leads to a relevant positive effect on the negative income-related inequality. Higher education, working and retired conditions explain all positive parts of the negative income-related inequality observed in new generation games $(4,19$, and $8 \%$ respectively in 2014, and 15,30 , and $3 \%$ respectively in 2017). In this case, highly educated, working, or retired people tend to play less to new generation games, but all these factors have positive concentration indexes since they are more concentrated among the richer individuals. Finally, the 
geographical component explains the $12 \%$ of income related inequality in new generation games in 2014 and the 3\% of income related inequality in 2017. As in other category of games, southern regions have higher rate of gamblers and a lower per-capita income level. These factors contribute positively to the negative incomerelated inequality observed in the new generation games.

Overall, the decomposition shown in Tables 6 and 7 reveals two distinct paths. The pro-rich inequality observed in traditional games is mainly driven by gender (males play more and have higher income), age (older people choose these games and are richer), and working condition (employed individuals play more at traditional games and are those with higher income). Conversely, the higher contribution to the pro-poor inequality observed in betting and new generation games is given by the income level (low income people prefer these games) and age (these games are more popular among younger people). This result remains substantially unchanged over the years (in 2014 and in 2017).

\section{Conclusions}

Gambling has become increasingly common in developed societies. In the Italian case, in line with the global trend, in the last decades there have been a series of reforms that have considerably expanded the gambling opportunities. In parallel, a massive expansion of the gambling market and an increasing prevalence of problematic gambling behavior have been observed. The different types of gambling products have contributed differently to this growing market and to the increasing gambling disorders. In particular, the growth in the gambling turnover observed in the last 16 years is mainly due to the revenues produced by betting and new generations games. Epidemiological literature has shown that these two categories of products are also strongly associated with problematic gambling behaviors. This paper contributes to investigate who is paying the increasing revenues and the increasing social costs associated to the spread of gambling. To this aim, we use the corrected Concentration Index proposed by Erreygers in 2009, which allows us to identify pro-rich and pro-poor games on a set of three categories of gambling products: Traditional games (Scratchcards, Instant Lottery, Lotto, and Bingo); Betting (Football pools and Sport betting); New generation games (Slot machines and Texas hold'em). Furthermore, we use a regression-based decomposition method for rankdependent inequality measures to assess the contribution that individual factors, such as income, gender, age, educational level, employment condition, and geographical region of residence, give to the income-related inequality observed in gambling. The estimates show that, taking all games together, gambling seems to be a prerogative of higher income people, since the Erreygers Index is positive although not significant. Differentiated results are instead obtained dividing the games into the three categories. Traditional games are more practiced by more well-off people both in 2014 and in 2017. Opposite results are instead found in Betting and New generation games which are both preferred by less well-off people, with an observed income-related inequality increasing over-time. Since these pro-poor games are also the major contributors of the growth in gambling turnover and the increase in gambling 
disorders, our results suggest that a relevant part of increasing social costs associated to gambling are more likely to be paid by the less-well off, and potentially most vulnerable members of the society. These results are in line Gandullia and Leporatti (2018) who found that in Italy the consumption of each game is unevenly distributed across Northern and Southern regions and that, in terms of distributional consequences, gambling products are generally regressive at a regional level.

Our regression-based decomposition reveals that pro-rich inequality observed in Traditional games is mainly driven by gender, age, and working condition. Conversely, the more relevant components of the pro-poor inequality observed in Betting and New generation games are income and age. This evidence remains substantially unchanged over the years (in 2014 and in 2017).

Today, aimed to massive budget shortfalls, politicians are scrambling to find new sources of revenue in the hope to solve economic issues. The results of this analysis share light on the spread of the gambling phenomenon in Italy and can be useful to design or reform targeted public policies, such as gambling taxation (e.g to discourage addictive games). Furthermore, this study can be used also as a tool to predict the distributional effect of introducing a specific product in the gambling market. From the public policy perspective, the effects of the expansion of gambling on low-income and therefore more disadvantaged individuals have failed to receive adequate consideration and our results show clearly that mainly poor people are paying for the increasing revenues.

Based on the increasing emergence of the gambling pathologies associated to new generation games, in particular entertainment machines, the Italian government has started to plan a progressive reduction of their supply and a reallocation in order to guarantee an adequate distance form places of public interest, like schools, hospitals and banks. This has generated a relevant policy debate that is still ongoing. Our findings provide some useful inputs in this respect. First, we find that entertainment machines are pro-poor games. Second, we also find that there are other pro-poor games, such as betting, which have seen an increase in the last years. Both types of games share the common characteristic of a high payout, which presumably is the main driver of the attractiveness for poor people wanting to achieve a higher position in the social hierarchy. This needs to be taken into consideration, as by limiting the availability of just one type of game the poor might shift to other games with the same attractiveness, i.e., betting.

Furthermore, the above mentioned spatial policies do not take account of the fact that there is already a gentrification phenomenon in Western economies, for which richer individuals tend to concentrate in urban areas while the less well-off are pushed at the periphery. Moving entertainment machines from public places, which are predominantly located in the city centers, to peripheral areas may have the unintended effect of making them closer to where the less well-of leave. This could directly increase the income-related inequality in gambling, as literature shows that availability and proximity are among the main drivers of gambling participation.

To discourage gambling engagement, our results support the literature calling for a reduction of the payout, as well as for educational and prevention programmes to limit the upsurge of gambling addiction. A way to achieve reduction of the payout could be to increase the tax-incidence, which has proved effective in discouraging risk behaviors associated to other "sin goods", such as tobacco and alcohol. Besides 
the usefulness in controlling market developments, the additional tax revenue raised can be used for worthy social purposes, e.g., funding social services (Clotfelter and Cook 1989). On this point there is consensus among economists that although earmarking gambling revenues can generate support by the public, it is often used as a political mean to neutralize opposition by socially concerned groups but usually covers a little proportion of total funding for such services (Smith 2000). This concern could be addressed by devolving the increased tax revenues to a targeted purpose, i.e., to mitigate the health and social issues created by the spread of gambling. In Italy, the National Health Service introduced in 1978 as a universal health care system providing comprehensive health insurance coverage and uniform health benefits to the whole population, has historically had a territorial redistributive role (Liberati 2003). Following a series of more recent reforms, although in compliance with national guidelines, regions are now responsible for the organization of their own health system. This produces a situation where gambling tax revenues are collected by the central government, but the social costs associated to the treatment of gambling addiction are borne by regions. As proposed by Gandullia and Leporatti (2018), this mismatch could be partially compensated by devolving the increased revenue to the regions in proportion to the contribution of their citizens to the generation of national gambling tax revenues. This would secure additional funding for those health care services devoted to problematic gamblers which have been recognized by the Government as essential to be guaranteed in all Italian regions. Southern regions, which are those more responsible for gambling consumption, in particular of pro-poor games, and therefore more likely to bear the social costs of gambling, but at the same time are those more lacking funding for their health care services, could particularly benefit from them. Finally, the evidence provided by the decomposition of the income inequality suggest that favoring policies aimed at increasing educational opportunities and reducing regional disparities may also indirectly help to reduce the pro-poor gambling engagement observed.

The main limitation of this study is the reliance on self-reported survey data. This concern is partially mitigated by the fact that the IPSAD ${ }^{\circledR}$ survey is anonymous and self-administered, whilst issues of truthfulness are more likely to arise when surveys are administered by personal interview. A further way to address this concern would be to expand our analysis including other outcome variables such as gambling turnover. Of course, such a gain would come at the price of losing individual information available in the case of survey data. A further limitation is that IPSAD ${ }^{\circledR}$ data do not contain the individual gambling expenditure by type of game, which would allow us to expand our analysis to investigate also the association between individual socio-economic position the amount that individuals spend on gambling.

This research may be extended by looking at different countries, although this perspective in inhibited by the fact that currently there are no comparable national general population surveys. Furthermore it would be interesting to focus the analysis on problematic gambling, as this might share new light on its socio-economic determinants. Lastly, the Erreygers index approach could be employed to compare the income-related inequality detected in gambling behavior with the income-related inequality present in other "sin goods" such as tobacco, alcohol and other psychoactive substances. 
Acknowledgements The authors wish to thank Vincenzo Carrieri, Owen O'Donnell, Paul Makdissi and Paolo Liberati for their useful suggestions. Furthermore, the authors are in debt with the participants of the Winter School 2019, HEALTH, OPPORTUNITIES AND REDISTRIBUTION held at Canazei 6-10 January 2019.

\section{Compliance with ethical standards}

Conflict of interests The authors declare that they have no conflict of interest.

Publisher's note Springer Nature remains neutral with regard to jurisdictional claims in published maps and institutional affiliations.

\section{Appendix}

Table A8 Income-related inequality by type of game for frequent gamblers* $(2014,2017)$
Table A9 Income-related inequality by type of game (2014, 2017) using the six classes of income in IPSAD (income not matched)

\begin{tabular}{lccclc}
\hline & Year & Obs. & EI & Std. error & $p$-value \\
\hline Gambler & 2014 & 697 & 0.012 & 0.008 & 0.127 \\
& 2017 & 686 & 0.009 & 0.010 & 0.354 \\
Traditional & 2014 & 267 & $\mathbf{0 . 0 2 1}$ & 0.005 & 0.000 \\
& 2017 & 275 & $\mathbf{0 . 0 2 8}$ & 0.006 & 0.000 \\
Betting & 2014 & 137 & $-\mathbf{0 . 0 1 4}$ & 0.004 & 0.000 \\
\multirow{3}{*}{ New generation } & 2014 & 120 & $-\mathbf{0 . 0 1 9}$ & 0.004 & 0.000 \\
& 2017 & 32 & -0.003 & 0.002 & 0.219 \\
& 2014 & 0.000 & 0.002 & 0.847 \\
\hline
\end{tabular}

Observations $=7348$ (2014); 5773 (2017). Gambler = at least weakly in the last 12 months; significant EI in bold.

*At least twice for a month in the last year. Column (2) reports number of observations, in column (3) the Erreygers Index is reported, column (4) reports standard errors, and column (5) report $p$ values for gamblers, gamblers in traditional games, gamblers in betting, and gamblers in new generation games

\begin{tabular}{lllll}
\hline & Year & EI & Std. error & $p$-value \\
\hline Gambler & 2014 & 0.015 & 0.011 & 0.197 \\
& 2017 & 0.020 & 0.014 & 0.152 \\
Traditional & 2014 & $\mathbf{0 . 0 3 9}$ & 0.008 & 0.000 \\
\multirow{2}{*}{ Betting } & 2017 & $\mathbf{0 . 0 4 4}$ & 0.010 & 0.000 \\
& 2014 & $\mathbf{- 0 . 0 3 4}$ & 0.006 & 0.000 \\
New generation & 2017 & $\mathbf{- 0 . 0 3 3}$ & 0.008 & 0.000 \\
& 2014 & $-\mathbf{0 . 0 1 1}$ & 0.004 & 0.002 \\
& 2017 & $\mathbf{- 0 . 0 1 0}$ & 0.004 & 0.007 \\
\hline
\end{tabular}

Observations $=7348$ (2014); 5773 (2017). Gambler $=$ at least weakly in the last 12 months; significant EI in bold. Column (2) reports number of observations, in column (3) the Erreygers Index is reported, column (4) reports standard errors, and column (5) report $p$ values for gamblers, gamblers in traditional games, gamblers in betting, and gamblers in new generation games 
G. Resce et al.

Table A10 Income-related inequality by type of game (2014, 2017)

\begin{tabular}{|c|c|c|c|c|}
\hline & Year & EI & Std. error & $p$-value \\
\hline \multirow[t]{2}{*}{ Gambler } & 2014 & 0.011 & 0.012 & 0.367 \\
\hline & 2017 & 0.015 & 0.015 & 0.329 \\
\hline \multirow[t]{2}{*}{ Scratchcard } & 2014 & 0.013 & 0.007 & 0.075 \\
\hline & 2017 & 0.004 & 0.009 & 0.659 \\
\hline \multirow[t]{2}{*}{ Instant Lottery } & 2014 & 0.000 & 0.004 & 0.974 \\
\hline & 2017 & 0.002 & 0.003 & 0.601 \\
\hline \multirow[t]{2}{*}{ Lotto } & 2014 & 0.053 & 0.007 & 0.000 \\
\hline & 2017 & 0.058 & 0.009 & 0.000 \\
\hline \multirow[t]{2}{*}{ Football pools } & 2014 & -0.001 & 0.003 & 0.662 \\
\hline & 2017 & -0.011 & 0.003 & 0.000 \\
\hline \multirow[t]{2}{*}{ Bingo } & 2014 & -0.015 & 0.002 & 0.000 \\
\hline & 2017 & -0.005 & 0.002 & 0.002 \\
\hline \multirow[t]{2}{*}{ Slot machines } & 2014 & -0.004 & 0.003 & 0.127 \\
\hline & 2017 & -0.004 & 0.003 & 0.124 \\
\hline \multirow[t]{2}{*}{ Sport betting } & 2014 & $-\mathbf{0 . 0 3 7}$ & 0.006 & 0.000 \\
\hline & 2017 & $-\mathbf{0 . 0 3 5}$ & 0.008 & 0.000 \\
\hline \multirow[t]{2}{*}{ Texas hold'em } & 2014 & -0.010 & 0.003 & 0.002 \\
\hline & 2017 & -0.007 & 0.003 & 0.010 \\
\hline
\end{tabular}

Observations $=7348$ (2014); 5773 (2017). Gambler $=$ at least weakly in the last 12 months; significant EI in bold. Column (2) reports number of observations, in column (3) the Erreygers Index is reported, column (4) reports standard errors, and column (5) report $p$ values for gamblers, and gamblers in each single game included in the data

Table A11 Regression results (probit model-2014)

\begin{tabular}{|c|c|c|c|c|c|c|}
\hline & \multicolumn{2}{|c|}{ Traditional } & \multicolumn{2}{|l|}{ Betting } & \multicolumn{2}{|c|}{ New generation } \\
\hline & Estimate & Std. error & Estimate & Std. error & Estimate & Std. error \\
\hline Intercept & -1.304 & $0.039 * * *$ & -1.417 & $0.047 * * *$ & -1.860 & $0.063 * * *$ \\
\hline Fractional Rank Income & 0.271 & $0.066 * * *$ & -0.499 & $0.088 * * *$ & -0.404 & $0.120 * * *$ \\
\hline
\end{tabular}

Observations $=7384$. Reported estimates in columns (1), (3), and (5) are from a probit regression. Columns (2), (4), and (6) are standard errors. Signif. codes: 0 ‘***' 0.001 ‘**' 0.01 ‘*' 0.05 '? 0.11

Table A12 Regression results (probit model—2017)

\begin{tabular}{|c|c|c|c|c|c|c|}
\hline & \multicolumn{2}{|c|}{ Traditional } & \multicolumn{2}{|l|}{ Betting } & \multicolumn{2}{|c|}{ New generation } \\
\hline & Estimate & Std. Error & Estimate & Std. Error & Estimate & Std. Error \\
\hline Intercept & -1.152 & $0.041 * * *$ & -1.195 & $0.045 * * *$ & -1.926 & $0.075^{* * *} *$ \\
\hline Fractional Rank Income & 0.275 & $0.069 * * *$ & -0.382 & $0.083 * * *$ & -0.440 & $0.145^{* *}$ \\
\hline
\end{tabular}

Observations $=5773$. Reported estimates in columns (1), (3), and (5) are from a probit regression. Columns (2), (4), and (6) are standard errors. Signif. codes: 0 ‘***’ 0.001 '**’ 0.01 ‘*’ 0.05 ' $\because 0.11$ 


\section{References}

Ariyabuddhiphongs, V. (2011). Lottery gambling: a review. Journal of Gambling Studies, 27, 15-33.

Bastiani, L., Gori, M., Colasante, E., Siciliano, V., Capitanucci, D., Jarre, P., \& Molinaro, S. (2013). Complex factors and behaviors in the gambling population of Italy. Journal of Gambling Studies, 29 (1), 1-13.

Beckert, J., \& Lutter, M. (2009). The inequality of fair play: lottery gambling and social stratification in Germany. European Sociological Review, 25(4), 475-488.

Beckert, J., \& Lutter, M. (2013). Why the poor play the lottery: sociological approaches to explaining class-based lottery play. Sociology, 47(6), 1152-1170.

Buth, S., Wurst, F. M., Thon, N., Lahusen, H., \& Kalke, J. (2017). Comparative analysis of potential risk factors for at-risk gambling, problem gambling and gambling disorder among current gamblersresults of the austrian representative survey 2015. Frontiers in psychology, 8, 2188.

Carrieri, V., Di Novi, C., \& Orso, C. E. (2017). Home sweet home? Public financing and inequalities in the use of home care services in Europe. Fiscal Studies, 38(3), 445-468.

Carrieri, V., \& Jones, A. M. (2016). Smoking for the poor and vaping for the rich? Distributional concerns for novel nicotine delivery systems. Economics Letters, 149, 71-74.

Carrieri, V., \& Wübker, A. (2013). Assessing inequalities in preventive care use in Europe. Health policy, 113(3), 247-257.

Cavalera, C., Bastiani, L., Gusmeroli, P., Fiocchi, A., Pagnini, F., Molinari, E., \& Molinaro, S. (2018). Italian adult gambling behavior: at risk and problem gambler profiles. Journal of gambling studies, 34 (3), 647-657.

Cerrai, S., Resce, G., \& Molinaro S. (2018). Consumi d'azzardo 2017 - Rapporto di Ricerca sulla diffusione del gioco d'azzardo fra gli italiani attraverso gli studi IPSAD ${ }^{\circledR}$ ed ESPAD ${ }^{\circledR}$ Italia, (a cura di) Cnr Edizioni, ISBN 9788880803010.

Clotfelter, C. T. (1979). On the regressivity of state-operated 'numbers' games. National Tax Journal, 32 (4), 543-548.

Clotfelter, C. T., \& Cook, P. J. (1987). Implicit taxation in lottery finance. National Tax Journal, 40(4), 533-546.

Clotfelter, C.T., \& Cook, P.J. (1989). Selling hope. Cambridge, MA: Harvard University Press.

Colasante, E., Gori, M., Bastiani, L., Siciliano, V., Giordani, P., Grassi, M., \& Molinaro, S. (2013). An assessment of the psychometric properties of Italian version of CPGI. Journal of Gambling Studies, 29(4), 765-774.

Combs, K. L., Kim, J., \& Spry, J. A. (2008). The relative regressivity of seven lottery games. Applied Economics, 40(1), 35-39.

Costa-Font, J., Hernández-Quevedo, C., \& Jiménez-Rubio, D. (2014). Income inequalities in unhealthy life styles in England and Spain. Economics \& Human Biology, 13, 66-75.

Coughlin, C. C., \& Garrett, T. A. (2009). Income and lottery sales: transfers trump income from work and wealth. Public Finance Review, 37(4), 447-469.

Crowley, F., Eakins, J., \& Jordan, D. (2012). Participation, expenditure and regressivity in the irish lottery: evidence from Irish household budget survey 2004/2005. The Economic and Social Review, 43(2), 199-225.

Deans, E. G., Thomas, S. L., Daube, M., \& Derevensky, J. (2016). "I can sit on the beach and punt through my mobile phone": the influence of physical and online environments on the gambling risk behaviours of young men. Social Science \& Medicine, 166, 110-119.

Di Bella, E., Gandullia, L., \& Leporatti, L. (2015). The impact of gambling on government budget: a european comparison with a focus on Italy. International Economics, 68(2), 187-212.

Doorslaer, E. V., Koolman, X., \& Jones, A. M. (2004). Explaining income-related inequalities in doctor utilisation in Europe. Health Economics, 13(7), 629-647.

D'Orazio, M. (2017). Statistical matching and imputation of survey data with StatMatch. R package version 1.2.5. https://CRAN.R-project.org/package=StatMatch.

Erreygers, G. (2009). Correcting the concentration index. Journal of Health Economics, 28(2), 504-515.

Farrell, L., \& Walker, I. (1999). The welfare effects of lotto: evidence from the UK. Journal of Public Economics, 72(1), 99-120.

Ferris, J. A., \& Wynne, H. J. (2001). The Canadian problem gambling index (pp. 1-59). Ottawa, ON: Canadian Centre on Substance Abuse.

Friehe, T., \& Mechtel, M. (2017). Gambling to leapfrog in status? Review of Economics of the Household, 15(4), 1291-1319. 
Gandullia, L., \& Leporatti, L. (2018). The demand for gambling in Italian regions and its distributional consequences. Papers in Regional Science, 97(4), 1203-1225.

Garrett, T. A., \& Coughlin, C. C. (2009). Inter-temporal differences in the income elasticity of demand for lottery tickets. National Tax Journal, 62, 77-99.

Ghent, L. S., \& Grant, A. P. (2010). The demand for lottery products and their distributional consequences. National Tax Journal, 63(2), 253.

Greco, S., Ishizaka, A., Matarazzo, B., \& Torrisi, G. (2018). Stochastic multi-attribute acceptability analysis (SMAA): an application to the ranking of Italian regions. Regional Studies, 52(4), 585-600.

Grote, K. R., \& Matheson, V. (2012). The economics of lotteries: a review of the literature. In L. V. Williams \& D. Siegel (Eds), Oxford handbook on the economics of gambling. London: Oxford University Press.

Guiso, L. (2016). Attenti a quei soldi: difendere le proprie finanze dagli altri e da sé stessi. EGEA spa.

Haisley, E., Mostafa, R., \& Loewenstein, G. (2008). Subjective relative income and lottery ticket purchases. Journal of Behavioral Decision Making, 21, 283-295.

Hansen, A. (1995). The tax incidence of the Colorado state lottery instant game. Public Finance Quarterly, 23, 385-398.

ISTAT (2018). Indagine su reddito e condizioni di vita (EU-SILC). Roma

Kearney, M. S. (2005). State lotteries and consumer behavior. Journal of Public Economics, 89(11-12), 2269-2299.

Khaled, M. A., Makdissi, P., Tabri, R. V., \& Yazbeck, M. (2018). A framework for testing the equality between the health concentration curve and the 45-degree line. Health economics, 27(5), 887-896.

Kjellsson, G., \& Gerdtham, U. G. (2013). On correcting the concentration index for binary variables. Journal of Health Economics, 32(3), 659-670.

Korn, D. A. (2000). Expansion of gambling in Canada: implications for health and social policy. Canadian Medical Association Journal, 163(1), 61-64.

Lagravinese, R., Liberati, P., \& Resce, G. (2019). Exploring health outcomes by stochastic multicriteria acceptability analysis: an application to Italian regions. European Journal of Operational Research, 274(3), 1168-1179.

Laitner, J. (1999). Means-tested public assistance and the demand for state lottery tickets. Economic Dynamics, 2(1), 273-290.

Layton, A., \& Worthington, A. (1999). The impact of socio-economic factors on gambling expenditure. International Journal of Social Economics, 26(1-2-3), 430-440.

Liberati, P. (2003). Fiscal federalism and national health standards in Italy: implications for redistribution. I sistemi di welfare tra decentramento regionale e integrazione europea. Franco Angeli, 241-273.

Ljungvall, Å., \& Gerdtham, U. G. (2010). More equal but heavier: a longitudinal analysis of incomerelated obesity inequalities in an adult Swedish cohort. Social Science \& Medicine, 70(2), 221-231.

Madhusudhan, R. G. (1996). Betting on casino revenues: lessons from state experiences. National Tax Journal, 49, 401-412.

Markham, F., Doran, B., \& Young, M. (2016). The relationship between electronic gaming machine accessibility and police-recorded domestic violence: a spatio-temporal analysis of 654 postcodes in Victoria, Australia, 2005-2014. Social Science \& Medicine, 162, 106-114.

Molinaro, S., Benedetti, E., Scalese, M., Bastiani, L., Fortunato, L., Cerrai, S., .. \& Fotiou, A. (2018). Prevalence of youth gambling and potential influence of substance use and other risk factors throughout 33 European countries: first results from the 2015 ESPAD study. Addiction, 113(10), $1862-1873$.

Olason, D. T., Kristjansdottir, E., Einarsdottir, H., Haraldsson, H., Bjarnason, G., \& Derevensky, J. L. (2011). Internet gambling and problem gambling among 13 to 18 year old adolescents in Iceland. International Journal of Mental Health and Addiction, 9(3), 257-263.

O’Donnell, O., Van Doorslaer, E., Wagstaff, A., \& Lindelow, M. (2007). Analyzing health equity using household survey data: a guide to techniques and their implementation. The World Bank, Washington, DC.

Paton, D., Siegel, D. S., \& Vaughan Williams, L. (2009). The growth of gambling and prediction markets: economic and financial implications. Economica, 76(302), 219-224.

Perez, L., \& Humphreys, B. R. (2011). The income elasticity of lottery: new evidence from micro data. Public Finance Review, 39, 551-570.

Pickernell, D., Brown, K., Worthington, A., \& Crawford, M. (2004). Gambling as a base for hypothecated taxation: the UK's national lottery and electronic gaming machines in Australia. Public Money \& Management, 24(3), 167-174.

Quiggin, J. (1991). On the optimal design of lotteries. Economica, 59(229), 1-16. 
Rivenbark, W. C., \& Rounsaville, B. B. (1996). The incidence of casino gambling taxes in Mississippi: setting the stage. Public Administration Quarterly, 20(2), 129-142.

Sarti, S., \& Triventi, M. (2012). Gambling: the iniquity of a voluntary tax. The relationship between socioeconomic position and propensity of gambling. Stato e mercato, Società editrice il Mulino. 3, 503-534.

Scalese, M., Bastiani, L., Salvadori, S., Gori, M., Lewis, I., Jarre, P., \& Molinaro, S. (2016). Association of problem gambling with type of gambling among Italian general population. Journal of Gambling Studies, 32(3), 1017-1026.

Scott, F., \& Garen, John (1994). Probability of purchase, amount of purchase, and the demographic incidence of the lottery tax. Journal of Public Economics, 54, 121-143.

Smith, J. (2000). Gambling taxation: public equity in the gambling business. The Australian Economic Review, 33, 120-144.

Suits, D. B. (1977). Gambling taxes: regressivity and revenue potential. National Tax Journal, 30(1), 19-35.

Szakmary, A., \& Szakmary, C. M. (1995). State lotteries as a source of revenue: a reexamination. Southern Economic Journal, 61, 1167-1181.

UPB (Parliamentary Budget Office). (2018) La fiscalità nel settore dei giochi. Focus tematico n. 6/3 maggio 2018. Rome.

Wagstaff, A., Paci, P., \& Van Doorslaer, E. (1991). On the measurement of inequalities in health. Social Science Medicine, 33(5), 545-557.

Worthington, A. C. (2001). Implicit finance in gambling expenditures: Australian evidence on socioeconomic and demographic tax incidence. Public Finance Review, 29, 326-342.

Worthington, A., Brown, K., Crawford, M., \& Pickernell, D. (2007). Gambling participation in Australia: findings from the national household expenditure survey. Review of Economics of the Household, 5 (2), 209-221. 